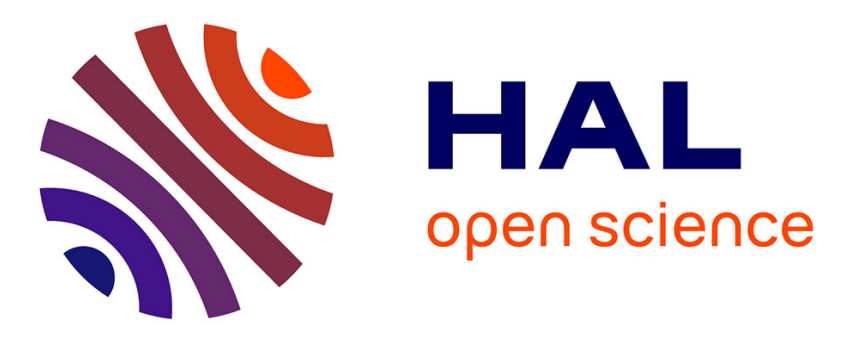

\title{
Multi-depth electrical resistivity survey for mapping soil units within two 3 ha plots
}

\author{
Solène Buvat, Julien Thiesson, Joël Michelin, Bernard Nicoullaud, Hocine \\ Bourennane, Yves Coquet, Alain Tabbagh
}

\section{- To cite this version:}

Solène Buvat, Julien Thiesson, Joël Michelin, Bernard Nicoullaud, Hocine Bourennane, et al.. Multidepth electrical resistivity survey for mapping soil units within two 3 ha plots. Geoderma, 2014, 232-234, pp.317-327. 10.1016/j.geoderma.2014.04.034 . insu-01010764

\section{HAL Id: insu-01010764 https://hal-insu.archives-ouvertes.fr/insu-01010764}

Submitted on 24 Jun 2014

HAL is a multi-disciplinary open access archive for the deposit and dissemination of scientific research documents, whether they are published or not. The documents may come from teaching and research institutions in France or abroad, or from public or private research centers.
L'archive ouverte pluridisciplinaire HAL, est destinée au dépôt et à la diffusion de documents scientifiques de niveau recherche, publiés ou non, émanant des établissements d'enseignement et de recherche français ou étrangers, des laboratoires publics ou privés. 


\title{
Multi-depth electrical resistivity survey for mapping soil units within two 3 ha plots
}

Solène Buvat ${ }^{1,2}$, Julien Thiesson², Joël Michelin³, Bernard Nicoullaud ${ }^{4}$, Hocine Bourennane ${ }^{4}$, Yves Coquet $^{1}$, Alain Tabbagh ${ }^{2}$

${ }_{1}^{1}$ UMR 7327, ISTO, Université d'Orléans, CNRS, INSU, Orléans, France

${ }^{2}$ UMR 7619, Sisyphe, UPMC/CNRS, Paris, France

${ }^{3}$ UMR EGC 1091, AgroParisTech, F-78850 Thiverval Grignon, France

${ }^{4}$ INRA, UR 272 Science du Sol, CS 40001 Ardon, 45075 Orleans Cedex 2, France

\begin{abstract}
Spatial information on soils generally results from local observations that are destructive and time consuming especially in the case of heterogeneous soils. Geophysical technics can be a great help for soil mapping since they are non-destructive and fast. Large areas can be surveyed with a high density of measurements. Electrical resistivity is particularly interesting for soil study because it covers a wide range of values (several decades) and depends on many characteristics of the soil.

The main objective of this paper was to study soil spatial variability using an original approach to electrical data processing. Electrical data from a 3-depths survey, usually treated as three apparent resistivity maps, were considered as many electrical soundings each with three apparent resistivity values. The study of the vertical succession of these values led to define nine reference geophysical taxa. This taxonomy relies on a parameter $(\alpha)$ which discriminates soil layers and is defined as the interval (in $\Omega \mathrm{m}$ ) beyond which two successive apparent resistivity values on a sounding are considered different. Geophysical taxa mapping highlighted their spatial coherence, which was related to pedological characteristics such as the presence of a clay layer or the depth of the soil profile. The comparison between the spatial distribution of
\end{abstract}


geophysical taxa and a pre-existing soil map showed that the delineations of taxa clusters closely matched soil units boundaries but were much less smooth. This method allowed the assignment to each soil type of a specific apparent electrical resistivity profile which was consistent with soil profile description. The method is straightly applicable to data from other surveys, and opens the way to the development of semi-automatic soil mapping from electrical resistivity data.

\title{
Key words
}

Soil mapping; geophysical taxonomy; electrical resistivity; spatial variability

\author{
Abbreviations \\ MU: map unit \\ DOI: depth of investigation \\ MLR: Multinomial logistic regression
}

\section{Introduction}

Spatial information on soils is usually based on 1) local observations (using auger soundings or opened pits) to recognize soil types and their characteristics, and 2) relationships between soil types and environmental factors (topography, geology, etc) in order to interpolate or extrapolate local observations. Direct soil observations are difficult to achieve, destructive and timeconsuming. Moreover, this typical approach reaches its limits when soil spatial variability is high or when the spatial distribution of soil does not appear to be related to environmental factors. In such situations, the use of geophysical technics to study soil is very relevant because they are non-destructive and fast, so that large areas can be surveyed rapidly.

In particular, electrical methods are interesting because various relationships between soil properties and electrical resistivity have been established (Corwin and Lesch, 2005; Friedman, 2005; McCutcheon et al., 2006; Samouëlian et al., 2005): among recent studies, electrical 
resistivity has been showed to be affected by stone content (Tetegan et al., 2012), by soil texture and especially by clay content (Auerswald et al., 2001) so that electrical resistivity measurements could be used to map the pedogenetic evolution of Luvic Cambisols (Nicole et al., 2003). Soil electrical resistivity is also related to soil structure and soil compaction resulting from traffic (Besson et al., 2004; Séger et al., 2009; Seladji et al., 2010) or tillage (Basso et al., 2010) allowing for the characterization of clods (Souffaché et al., 2010) or cracks in soils (Samouelian et al., 2004, 2003; Tabbagh et al., 2007). Since water content has an impact on soil resistivity, electrical methods can be helpful to map soil water content (Besson et al., 2010; Cousin et al., 2009), to study evapotranspiration effect in relation to row crops (Panissod et al., 2001; Tabbagh et al., 2002) and for time-space monitoring of soil water status (Batlle-Aguilar et al., 2009; Brunet et al., 2010; Garre et al., 2012; Michot et al., 2003). The fact that soil electrical resistivity is related to several soil properties makes it an interesting proxy for soil mapping. Fast mobile devices for measuring soil electrical resistivity from the soil surface (Hesse et al., 1986; Panissod et al., 1998, 1997a, 1997b) allow a high spatial density of measurements to be taken with various depths of investigation (DOI). These devices proved very effective in giving geometrical soil information such as depth to the substratum (Chaplot et al., 2001; Moeys et al., 2006) or horizon thickness (Chaplot et al., 2010). If the electrical method can be a good tool to help soil mapping (Dabas et al., 1989; Tabbagh et al., 2000), the interpretation of soil electrical resistivity data in terms of pedological profiles or pedological volumes remains difficult. Data from three-depths electrical resistivity surveys as used in this study give three parameters to describe the soil profile, which may be sufficient if the soil profile corresponds to a geoelectrical model with two layers (two parameters for the resistivities of the two layers and one for the thickness of the first one) (Robain et al., 2001). Theoretically, more complex soils require more measurements.

Although using data from three-depths electrical resistivity surveys, this study tries to bypass this problem. The electrical resistivity data, usually treated as three separate apparent resistivity maps, are considered here as a multitude of electrical soundings, each with three apparent 
resistivity values. Based on the evolution of resistivity with depth of each sounding, i.e. the vertical succession of the three apparent resistivity values, a geophysical taxonomy was established. The aim of this paper is to evaluate the potential of three-depths electrical resistivity surveys for soil mapping by comparing the spatial distributions of geophysical taxa to an existing soil map and by trying to retrieve soil unit boundaries through the delineation of geophysical taxa clusters. To this aim, relationships between typological soil profiles and apparent resistivity profiles were set up so that specific electrical signatures could be found out for each soil map unit (MU).

\section{Materials and methods}

\subsection{Site description}

The studied site is a cultivated field of 22.5 ha, located in the Beauce region (Parisian Basin in France) characterized by a thick layer of Beauce limestone (from 10 to $100 \mathrm{~m}$ in thickness), which may include locally some alluvium deposits, overlaid by wind-blown loess. A soil map of the field has been established by Moeys et al. (2006) (figure 1). It revealed the large spatial variability of the soil, which is mainly related to the depth to the limestone bedrock, the presence of a clay layer in between the silt loam loess-derived deposit and the limestone, and the content in coarse elements. Two 3 ha areas, identified as West and East areas in the figure 1, were focused on because of their large contrast in soil type. The West area presents a NW-SE lateral variability with deep Luvic Cambisols (MUs 13 and 14) whose calcareous substratum appears at more than $95 \mathrm{~cm}$ depth at the NW, and, at the SE of the area, shallow Calcaric Cambisols and Hypereutric Cambisols (MU 5) whose cryoturbed calcareous substratum appears between 30 and $50 \mathrm{~cm}$ depth. A strip of colluvic Cambisols (MU 15), with a calcareous substratum at $55 \mathrm{~cm}$ in average, separates these two areas. The East area includes deep Luvic Cambisols on heavy clay (MU 2) with limestone bedrock at a depth larger than $105 \mathrm{~cm}$. MUs 1 and 3 correspond to Luvic Cambisols on cryoturbed limestone with an average depth to the bedrock of $75 \mathrm{~cm}$ and $55 \mathrm{~cm}$, respectively. MU 4 is composed of two types of soil: Luvic 
Cambisols and Hypereutric Cambisols on cryoturbed limestone with an average depth to the bedrock of $55 \mathrm{~cm}$ and $40 \mathrm{~cm}$, respectively. The main characteristics of each unit are summed up in table 1.

\subsection{Multi-depths electrical resistivity survey}

Device

Electrical resistivity measurements were obtained using an automatic resistivity profiling device $\left(\mathrm{ARP}^{\circledR},{ }^{\circledR}\right.$ Geocarta, Paris, France), which is a mobile multi-electrode system pulled by an off-road vehicule. It is a V-shaped array (Panissod et al., 1997a) composed of three measurement dipoles (V1, V2, V3 channels) and one injection dipole inserted into the topsoil. The distance between the injection electrodes and the voltage measurement electrodes is $0.5 \mathrm{~m}$ for the $\mathrm{V} 1$ array, $1 \mathrm{~m}$ for the V2 array and $2 \mathrm{~m}$ for the V3 array (figure $2 \mathrm{a}$ ). The main advantages of this configuration are that: (i) it makes the survey of large areas fast, (ii) the spatial density of measurements is very high (every $13 \mathrm{~cm}$ along the device moving direction) and (iii) 3 apparent resistivity values are acquired simultaneously. The lateral positions of the three measurement points taken simultaneously are assumed to be at the center of the array (crosses in figure 2a). The three electrode arrays, of different geometry and dimension, allow to investigate from the surface three volumes of soil of increasing size down to the three theoretical depths of investigation (DOI), estimated to $0.5,1$ and $1.7 \mathrm{~m}$. These DOI are materialized by crosses in figure $2 \mathrm{~b}$ and the big crosses illustrate the lateral relationship between the three simultaneous measurements acquired by the three arrays.

\section{Acquisition}

Profiles (passages of the device) were $1 \mathrm{~m}$-spaced and were made along the longitudinal direction of the field (figure 1). The $1 \mathrm{~m}$ spacing was chosen so as to detect metric contrasts in the soil as currently found in the Parisian Basin (Dabas et al., 1995). All data were converted to

apparent resistivity using the relation $\rho_{a}=k_{i} \frac{\Delta V}{I}$ with $i=1,2,3$ for each array and where 
$I=1 \mathrm{~mA}$ is the injected current, $\Delta V$ is the electrical potential difference measured between electrodes $M_{i}$ and $N_{i}$ and $k_{i}=\frac{\pi}{\frac{1}{A M_{i}}-\frac{1}{A N_{i}}}$ is the geometrical parameter for each array $i$ : $k_{1}=4.63 \mathrm{~m}, k_{2}=10.73 \mathrm{~m}, k_{3}=51.10 \mathrm{~m}$. The system is completed by a resistivity meter (AFM 05 ). All measurements (about 380,000 for each area and for each array) were georeferenced using a StarFire differential GPS and recorded on a PC. The electrical surveys were achieved in August 2010.

\section{Data preprocessing}

As the three apparent resistivity values measured by the three arrays are not centered at the same point (figure $2 \mathrm{~b}$ ), data were interpolated by a cubic function to obtain the values at the same coordinates $\mathrm{X}$ and $\mathrm{Y}$ i.e. on the same vertical profile. These three values can be interpreted as a usual electrical sounding. The size of the interpolation grid was $1 \mathrm{x} 1 \mathrm{~m}$. A median filter has been used (size $5 \times 5 \mathrm{~m}$ ) to limit the effect due to the disking of rapeseed stubble done before the resistivity measurements.

\subsection{Geophysical taxonomy}

A taxonomy of reference electrical soundings, based on the evolution of the three values of apparent resistivity with depth, was proposed. It uses a parameter, $\alpha$, which is the apparent resistivity interval in $\Omega \mathrm{m}$ beyond which two successive apparent resistivity values are considered different, proving the presence of different soil layers in the profile. The parameter $\alpha$ can be viewed as a mean to differentiate more or less the soil layers from the point of view of their electrical resistivity. According to the succession of the 3 apparent resistivity values with depth, 9 types of vertical profiles can be assumed (figure 3). Taxon names in figure 3 include two letters to describe the evolution of the resistivity with depth. The first letter describes the evolution of resistivity from $\rho_{a} 1$ (measured by array 1 , figure 2) to $\rho_{a} 2$ (measured by array 2), 
and the second from $\rho_{\mathrm{a}} 2$ to $\rho_{\mathrm{a}} 3$ (measured by array 3). The letters "I", "D" or "C" are used for an "increasing", "decreasing" or "constant" resisitivity variation with depth, respectively.

The soil is thus interpreted as:

(i) homogeneous if the three apparent resistivity values are in the range $[\rho-\alpha, \rho+\alpha]$; the corresponding taxon is named $\mathrm{C}-\mathrm{C}$,

(ii) a two-layers soil if the difference between two contiguous values is less than or equal to $\alpha \Omega \mathrm{m}$ (the two values result from the response of the same layer) and larger than $\alpha \Omega \mathrm{m}$ for the other two contiguous values; the four corresponding taxa are noted C-I, I-C, C-D and D-C. As an example, the taxon C-I means that $\rho_{\mathrm{a}} 1$ and $\rho_{\mathrm{a}} 2$ are considered equal and belonging to the same conductive upper layer, and that the $3^{\text {rd }}$ resistivity value $\rho_{\mathrm{a}} 3$ results from a resistant bottom layer,

(iii) a three-layers soil if the difference between any two contiguous values is more than $\alpha \Omega \mathrm{m}$; the four corresponding taxa are noted I-I, D-D, I-D and D-I.

The discrimination of the soil layers will be maximal for $\alpha=0 \Omega \mathrm{m}$ and no soil layers will be distinguished for large values of $\alpha$.

\subsection{Similarity between experimental and reference geophysical taxa}

To avoid any a priori choice of a particular $\alpha$ value, a range of values for the $\alpha$ parameter was considered and a matrix form was used to estimate the similarity between experimental geophysical taxa and reference geophysical taxa.

\section{Experimental taxon matrix E}

A matrix $E$ of dimension $(3,3)$ was assigned to each experimental sounding. This matrix is the product of two vectors expressing the sign of the difference between two adjacent values of apparent resistivity $(>0,<0$ or $=0$ for an increasing, decreasing evolution or no evolution, respectively) (figure 4). The numerical values of the matrix elements change when the $\alpha$ parameter increases as described hereafter. At the start of the process, for $\alpha=\alpha_{\min }$, the matrix is 
null. For each new value of $\alpha$ tested, from $\alpha_{\min }$ to $\alpha_{\max }$, the sounding is interpreted as one of the nine geophysical taxa defined above (figure 3) and the element of $E$ corresponding to the taxon (figure 4) is incremented by the step value $\Delta \alpha=\alpha_{i+1}-\alpha_{\mathrm{i}}$. The matrix is filled until $\alpha$ reaches its final value $\alpha_{\max }$ Thus the matrix $E$ keeps the history of the sounding evolution while the $\alpha$ parameter scans the range of resistivity values tested from $\alpha_{\min }$ to $\alpha_{\max }$. The larger element of the $E$ matrix gives the more likely taxon in terms of geophysical interpretation.

\section{Reference taxon matrix $R$}

A matrix $R$ of dimension $(3,3)$ was assigned to each of the nine reference geophysical taxa defined in section 2.3. These nine $R$ matrices are null matrices with only one element equal to 1 . The nonzero element is positioned in $R$ at the place corresponding to the reference profile (figure 4). For example, the matrix $\left[\begin{array}{lll}1 & 0 & 0 \\ 0 & 0 & 0 \\ 0 & 0 & 0\end{array}\right]$ is used to express the I-I-type reference profile, and $\left[\begin{array}{lll}0 & 0 & 0 \\ 0 & 1 & 0 \\ 0 & 0 & 0\end{array}\right]$ to express the C-C-type profile corresponding to a homogeneous soil.

\section{Distance between matrices $E$ and $R$}

Using these matrix forms, the distance $d$ between matrices $E$ and $R$ could be calculated. This distance reflects the degree of similarity between each experimental sounding and each reference taxon. The distance $d$ is given by the norm of the difference between $E$ and $R$ and corresponds to the quadratic sum of the elements of the matrix $E-R$. It is expressed as:

$$
d=\|E-R\|=\sqrt{\sum_{i=1, j=1}^{m, n}(E-R)_{i, j}^{2}}, \quad(\mathrm{~m}=3, \mathrm{n}=3)
$$

The lower $d$ is, the more similar $E$ and $R$ are. The nine distance values per sounding $d_{I-I}, d_{I-C}, d_{I-D}$, $d_{C-I}, d_{C-C}, d_{C-D}, d_{D-I}, d_{D-C}$ and $d_{D-D}$ were normalized by dividing them by the sum of all $\sum_{i=1}^{9} d_{i}$. We were then able to draw nine distance maps, also called similarity maps.

\subsection{Expected geophysical taxon according soil MU}


Each unit of the soil map was characterized by a typical soil profile, except for the complex MU 4, which is composed of a mix of two types of soil: shallow Hypereutric Cambisols and Luvic Cambisols. Each soil profile could be assigned an expected geophysical taxon based on the vertical succession of the different horizons composing the soil profile and the expected electrical resistivity contrasts between them. For instance, a shallow Hypereutric Cambisol has a silt loam cultivated topsoil overlaying a shallow (less than $20 \mathrm{~cm}$-thick) non carbonated structural horizon, above the limestone substrate. The cultivated topsoil can be expected to have a higher electrical resistivity than the underlaying undisturbed structural horizon because tillage tends to disrupt the continuity of the soil solid phase and creates interclods voids, which should increase soil resistivity (Samouelian et al., 2004). On the other hand, the untilled structural horizon should have a lower resistivity than the underlaying limestone because of its larger content in clay minerals. As a result, a shallow Hypereutric Cambisol should correspond to the D-I geophysical taxon or, if the topsoil and the underlaying structural horizon do not have sufficiently contrasted resistivities, to the C-I geophysical taxon. The same type of reasoning can be applied to each typological soil unit to get the most likely geophysical taxon or taxa for each soil map unit (table 1).

\subsection{Statistical evaluation: Multinomial Logistic Regression}

Multinomial logistic regression (MLR) was used to evaluate the ability of geophysical taxa mapping to predict the available soil map. Multinomial logistic regression is the extension for the binary logistic regression when the categorical dependent outcome (here, the soil MU) has more than two levels.

The goal of multinomial logistic regression is to estimate the probability of each class (each soil MU) using a same set of influencing variables (the geophysical taxa). The model is similar to the binomial logistic regression in the sense that the logarithm of the odds ratio is assumed to be a linear function of the influencing variables. However, one of the classes is taken as the baseline 
and odd ratios are developed for all other classes with respect to this baseline. For a thorough presentation, the reader can refer to Hosmer and Lemeshow (2000) or Agresti (2002). Nonetheless, a brief presentation is given below concerning the binomial logistic model and its generalization to the multinomial case.

In the binomial logistic regression, the probability $\left(p_{1}\right)$ that an object belongs to a group 1 (e.g., a particular soil $\mathrm{MU}$ ), and the probability $\left(p_{2}\right)$ that it belongs to a group 2 (another soil $\mathrm{MU}$ ), according to a set of predictor variables (presence or absence of each geophysical taxon), are given by the logit link function:

$$
\operatorname{logit}\left(p_{1}\right)=\operatorname{Ln}\left(p_{1} / p_{2}\right)=\operatorname{Ln}\left(p_{1} / 1-p_{1}\right)=\mathbf{x} \beta
$$

where $\mathbf{x}$ is a vector of predictor variables, and $\beta$ is a vector of model coefficients that are usually estimated by maximum likelihood.

The expression (2) can be rewritten as:

$$
\frac{p_{1}}{1-p_{1}}=\exp (\eta)
$$

The left term in (3) is called the odds ratio. From expression (3) follows that:

$$
p_{1}=\frac{\exp (\eta)}{1+\exp (\eta)}
$$

The binomial logistic regression model can be generalized to the multinomial case where the number of logistic functions is one less than the number of groups. For example if there are three groups, one of the groups is taken to be a reference group (say group 0), so that the first logistic function can be used to predict the probability that an object will belong to group 1 rather than group 0 , and the second logistic function can be used to predict the probability that an object will belong to group 2 rather than group 0 .

\section{Results}

\subsection{Electrical survey}


The apparent resistivity data are presented in the form of three maps corresponding to the different measuring dipoles (figure 5). These maps represent the contribution of the cumulative soil volume, from the surface down to the three depths of investigation, $0.5,1$ and $1.7 \mathrm{~m}$ for arrays 1, 2 and 3, respectively. Maps resulting from the first array measurements are affected by the effect of rapeseed stubble disking which appears as lines oriented in the direction of agricultural machinery traffic (McCutcheon et al., 2006). Apart from that, no contrast were clearly identifiable despite apparent resistivity values that extend from 50 to $90 \Omega \mathrm{m}$. Maps from array 2 measurements both show located conductive areas: the west part of area West and the SE corner of area East. These conductive areas are exacerbated on maps resulting from array 3 measurements and present resistivity values from 30 to $50 \Omega \mathrm{m}$ on area West and from 7 to $30 \Omega \mathrm{m}$ on area East. By comparing this figure with the soil map in figure 1, it can be seen that the conductive zones correspond to deep Luvic Cambisols (MUs 13, 14 and 2).

\subsection{Geophysical taxa mapping for various $\alpha$}

Figure 6 shows the spatial distribution of geophysical taxa in each area for different values of $\alpha$ in the range 2 to $7 \Omega \mathrm{m}$, together with map excerpts from figure 1 corresponding to each area. The matrix distances described in section 2.4 were calculated using the same range of resistivity values. The initial value of $\alpha$ was chosen not too small in order to avoid systematic 3-layers interpretations which would be not consistent with soil description. In the same manner, the maximum $\alpha$ value was chosen not too large so that soundings would not be systematically interpreted as homogeneous soils, which would not be consistent with soil description either. So, the $E$ matrix assigned to each electrical sounding summarized the evolution of the sounding interpretation within the $\alpha$ range 2-7 $\Omega \mathrm{m}$. The similarity between experimental soundings and each reference taxon is mapped in figure 7.

\section{West area}

The predominant taxa in the West area for $\alpha=4 \Omega \mathrm{m}$ were D-D-type (which covered $31 \%$ of the surface), I-I-type (16\%), C-I-type (9\%) soundings and that corresponding to a homogeneous soil 
(C-C-type, 26\%) (figure 6a), which correspond also to the maximum similarities (smaller distances) calculated in figure $7 \mathrm{a}$. Each of the other taxa covered no more than $5 \%$ of the area. Obviously, the map may be split into two parts. There is a strong spatial coherence of D-D-type soundings, which gather on the NW of the map (figure 7a). I-I-type and C-I-type soundings are completely absent from this half of the surveyed area, but cover a large part of the SE. Furthermore, a significant amount of soundings corresponding to a homogeneous soil are present on the surveyed area even for low values of $\alpha$ (3-4 $\Omega \mathrm{m}$, figure 6a). They are concentrated in the SE of the map and in a strip along the axis NNE-SSW (figure 7a) that appears as a transition between the two clusters mentioned above.

\section{East area}

Six geophysical taxa were present in the East area (figures $6 \mathrm{~b}$ and $7 \mathrm{~b}$ ). For $\alpha=4 \Omega$.m, I-I-type (6\%) and C-I-type (19\%) soundings were mostly found in the $\mathrm{N}$ of the map, while D-D-type (11\%) and D-C-type (16\%) soundings covered the center and the S of the map (figure 6b). Among the nine taxa defined, the D-I and C-C-type were the most abundant in this area $(26 \%$ and $22 \%$ for $\alpha=4 \Omega \mathrm{m}$, respectively) and covered all the area to the exception of the SE corner. Other sounding types (namely I-D, I-C, and C-D) were almost inexistent in the area (figure 7b). The distributions of these three couples of taxa (I-I and C-I types, D-D and D-C types, and D-I and C-C types), which were found spatially associated in the East area, remain almost unchanged according to the value of the $\alpha$ parameter (figure $6 \mathrm{~b}$ ) but there is a change of type of resistivity profile within each couple when $\alpha$ increases. When $\alpha$ increases, D-I-type, I-I-type and D-D-type soundings tend to be converted to C-C-type (homogeneous soil), C-I-type and D-C-type, respectively. As expected, the increase of $\alpha$ changes the interpretation of the geophysical data: low values of $\alpha$ lead to a 3-layers soil interpretation, while large values of $\alpha$ lead to soils with one or two layers.

\subsection{Concordance between geophysical taxa maps and soil map}

\section{West area}


The D-D-type geophysical taxa cluster found at the NW of the area corresponds to the deep Luvic Cambisols of MUs 13 and 14 (figure 6a). The D-D-type sounding expresses a resistivity decreasing with depth, which is consistent with the fact that deep Luvic Cambisols have a clay content that increases with depth as a result of clay illuviation. The lack of discrimination between MUs 13 and 14 probably reflects a poor resistivity contrast between their substratum (heavy burhstone clay over deep limestone for MU 13 vs redish loam for MU 14). The NNE-SSW strip of homogeneous soil is perfectly consistent with the colluvic nature of MU 15, as colluvium lacks pedological stratification. The rest of the area is mostly occupied by MU 5, which corresponds to shallow Calcaric and Hypereutric Cambisols. These shallow soil profiles developed over limestome are consistent with I-I-type soundings, where resistivity increases with depth, and eventually with C-I soundings where resistivity increases only in the lower part of the soil profile. This last case probably reflects a larger depth to the limestone substrate. The larger abundance of C-C-type soundings further at the East side of the area might be an indication of the more conductive substratum of MU 7 (buhrstone clay), but this MU does not extend as far to the south as C-C-type soundings (figure 6a).

\section{East area}

A very distinct cluster of D-D-type soundings occupies the SE of the area, which corresponds quite well with the deep Luvic Cambisols of MU 2 (figure 6b). As in the West area, I-I-type and CI-type soundings were consistent with the MUs composed of shallow Hypereutric and Luvic Cambisols, i.e. MUs 3 and 4, for which the superficial ploughed layer lays sometimes directly above the resistive substratum. Although D-I-type soundings would have been expected for Luvic Cambisols as a result of a resistive ploughed layer overlaying an illuviated clay layer over a cryoturbated limestone, the shallow depth to bedrock $(55 \mathrm{~cm})$ and a limited illuviation could explain the undetectable resistivity contrast between the topsoil layer and the contiguous illuviated horizon. The rest of the area, occupied by MU 1, predominantly includes D-I profiles (figure 6b), which is consistent with the presence of Luvic Cambisols having a larger depth to the substratum than the Luvic Cambisols of MUs 3 and 4, but not so as to lead to D-D-type soundings 
as in MU 2. The shallow Calcaric and Hypereutric Cambisols of MU 5 could not be identified from the geophysical taxa map. These observations are summarized in table 1 (column 6).

Limits of taxa clusters could be drawn on the geophysical taxa map (figure 6 for $\alpha=4 \Omega \mathrm{m}$ ) using the distance maps of figure 7 . The delineations of taxa clusters were found to closely match soil unit boundaries. The best delineations were obtained for the deep Luvic Cambisols of MUs 13 and 14 in the West area and MU 2 in the East area. These MUs are mostly filled with D-D-type soundings. This sounding is the most consistent to express a decreasing resistivity with depth due to the clay gradient found in deep Luvic Cambisols. This result shows how the presence of clay significantly plays a prominent role in electrical resistivity measurements.

\subsection{Evolution of geophysical taxa occurrence with $\alpha$}

Figure 8 represents the occurrence of each of the nine geophysical taxa found in each main MU of the surveyed areas as a function of $\alpha$. It illustrates how soundings interpretation changes when $\alpha$ increases. These graphs can be used to specify the values of the parameter $\alpha$ for which there is a best similarity between the interpreted soundings and those expected according to pedological description.

Map units 2, 13 and 14: deep Luvic Cambisols

D-D-type soundings on MUs 2, 13 and 14 are obtained for a large range of $\alpha$ values starting from 0 to 8,16 and $11 \Omega \mathrm{m}$, respectively (figure 8). Moreover, most D-D-type soundings of MU 2 change into D-C-soundings for $8<\alpha<25 \Omega \mathrm{m}$ before matching with those corresponding to a homogeneous soil. This progression implies a resistivity contrast in MU 2 such as $\rho_{\mathrm{a}} 1>>\rho_{\mathrm{a}} 2>\rho_{\mathrm{a}} 3$.

Map unit 5: shallow Calcaric Cambisols and shallow Hypereutric Cambisols on cryoturbed limestone at $35 \mathrm{~cm}$ and $41 \mathrm{~cm}$, respectively 
I-I-type soundings are predominant in MU 5 up to $\alpha=5.5 \Omega \mathrm{m}$ and beyond this value there is a majority of resistivity profiles corresponding to a homogenous soil. The expected C-I-type soundings are present in the MU, but never predominant. The maximum density of C-I profiles in MU 5 was obtained for around $\alpha=7 \Omega \mathrm{m}$.

Map units 3 and 4: Luvic Cambisols and shallow Hypereutric Cambisols on cryoturbed limestone at $55 \mathrm{~cm}$ and $37 \mathrm{~cm}$, respectively

Taxa distribution progression in MUs 3 and 4 are very similar. MU 4 is a complex unit of Luvic Cambisols and shallow Hypereutric Cambisols. Shallow Hypereutric Cambisols are perhaps poorly represented compared to Luvic Cambisols in MU 4 so that it could explain the similarity between the two graphs. D-I-type soundings are the most present (about 2/3 to 1/3 of the total) in the two MUs for small values of $\alpha$ up to $4-4.5 \Omega \mathrm{m}$ but they have no specific spatial coherence as can be seen in figure 6b. C-I-type soundings are the most abundant (up to $40-50 \%$ ) for $4.5 \Omega \mathrm{m}<\alpha<9.5 \Omega \mathrm{m}$ in MU 3 and for $4 \Omega \mathrm{m}<\alpha<12 \Omega \mathrm{m}$ in MU 4 (figure 8) and are more clearly delimited (figure 7). This evolution of the taxa distribution according to $\alpha$ suggests a resistivity contrast in both MU 3 and 4 ordered as $\rho_{\mathrm{a}} 1>\rho_{\mathrm{a}} 2<<\rho_{\mathrm{a}} 3$.

Map unit 1: Luvic Cambisols on cryoturbed limestone at $75 \mathrm{~cm}$

The expected D-I-type soundings predominance in MU 1 is obtained for $0 \Omega \mathrm{m}<\alpha<5.5 \Omega \mathrm{m}$ (figure 8). However resistivity profiles turn rapidly into those corresponding to a homogenous soil.

Map unit 15: Colluvic Cambisols on cryoturbed limestone

I-I-type soundings are predominant in MU 15 for low values of parameter $\alpha$. Other taxa are also present, but C-C-type soundings were expected for this MU. For Colluvic Cambisols to be viewed as uniform soils, the most appropriate $\alpha$ values are beyond $5 \Omega \mathrm{m}$.

The two last column of table 1 give the dominant geophysical taxon (or taxa) observed in the range of $\alpha$ values indicated for each MU. The analysis of these values shows that the parameter $\alpha$ 
does not need to be large (i.e. $<16 \Omega \mathrm{m}$ ) to have correct results. Most apparent resistivity profiles obtained experimentally were consistent with soil descriptions (in bold in table 1). Nevertheless, it remains difficult to assign a particular value to the parameter $\alpha$ such that there is, for all MUs, a systematic concordance between the reference taxa expected according to soil description and the experimental resistivity profiles obtained by electrical prospecting. Ultimately, no optimal value for $\alpha$ could be found.

\subsection{Multinomial logistic regression}

The ability of geophysical taxa mapping to match the available soil map (figure 1) was evaluated using MLR.

\section{West area}

Very good predictions were obtained for MUs 13, 14 and 5, for which percentages of correct classification were higher than $75 \%$ (table 2). The lower performance of MU 14 assignments is probably due to the lower purity of this MU compared to MU 13 as stated above. Around $23 \%$ of the geophysical taxa within MU 14 were assigned to MU 5 while only $3 \%$ of the geophysical taxa located in MU 13 were assigned to MU 5. MU 15 could not be retrieved through MLR prediction. However, a band of C-C- type geophysical taxa could be clearly delineated and interpreted as Colluvic Cambisol (figure 6a) just like the soil corresponding to MU 15. The inability of the method to retrieve this MU 15 is probably due to the fact that MU 15 and the band of C-C-type taxa delineated in figure $6 \mathrm{a}$ (for $\alpha=4 \Omega \mathrm{m}$ ) do not match exactly in terms of geographical location and shape.

East area

Very good predictions were also obtained for MUs 1 and 2, but not for MUs 3 and 4 (table 2). MU 3 could not be retrieved through MLR prediction, and MU 4 was correctly classified for only $13 \%$ of its extent. Here again, the fact that the delineations of the geophysical taxa in figure $6 \mathrm{~b}$ (for $\alpha=4 \Omega \mathrm{m}$ ) do not match those of the MUs is probably the reason for the poor prediction found 
for MUs 3 and 4. When considering the soil map, MUs 3 and 4 appear as patches within MU 1. If these patches are not precisely located and delineated, it could explain their poor prediction while MU 1 is well predicted.

\section{Discussion}

\subsection{Advantages of the method}

The original method presented here is based on a simple interpretation of the geophysical data acquired at very high spatial density by an automatic resistivity profiling tool. It makes use of all the generated data to produce locally-interpreted soundings in term of soil profile organisation. This information could be used to improve the delimitations between soil map units, and to quantify objectively the purity of soil map units.

Map unit purity

Geophysical taxa mapping may be a good tool to indicate the purity of MUs. For example, D-Dtype soundings corresponding to deep Luvic Cambisols cover 94\% of MU 13 for $\alpha=4 \Omega \mathrm{m}$ (figure 6a), but only 63\% for MU 14 and $69 \%$ for MU 2 (figure $6 \mathrm{~b}$ ) for the same $\alpha$ value. In contrast, MU 1 was mainly characterized by D-I-type soundings, which correspond to Luvic Cambisols, but they represented only $30 \%$ of the MU (for $\alpha=4 \Omega \mathrm{m}$ ), while the remaining of the MU was mostly composed of C-I-type (15\%), D-C-type (19\%) and C-C-type (25\%) soundings. This shows that MU 1 was not very pure probably because the depth to the bedrock in area East was highly variable.

\section{Taxa clusters delineations}

Boundaries between soil units in a soil map result from the interpolation of local pedological observations. Geophysical taxa clusters delineation results from numerous electrical resistivity measurements (figure 6). They are less smooth than soil map boundaries but probably more realistic. The drawing of soil unit delimitations can be significantly improved by means of high density electrical measurements. 


\subsection{Limits of the method}

Taxa or distance mapping could not reveal the difference between Hypereutric Cambisols (MU 4) and Luvic Cambisols (MUs 3 and 4) whose bedrock appears at less than $60 \mathrm{~cm}$ depth. One hypothesis to explain this result is that taxon I-I would be attributable to very shallow soils as Hypereutric Cambisols in MU 4 (or Calcaric Cambisols in MU 5) and taxon C-I to Luvic Cambisols as found in MUs 3 and 4. In this case, the complex MU 4, mainly covered by the C-Itaxon was probably composed of Luvic Cambisols rather than Hypereutric Cambisols, thus explaining the lack of distinction between MUs 3 and 4. The fact that the Luvic Cambisols of MUs 3 and $4(\sim 55 \mathrm{~cm}$ depth) were represented by taxon C-I and not by taxon D-I as expected, was probably due to a too weak differentiation of the Luvisols. The clay content of the BT layer could be not different enough from that of the top soil layer, resulting in a low resistivity contrast between surface and BT layers, and thus the electrical measurements may have been not able to detect this low contrast. A substantial resistivity contrast is probably necessary to distinguish between different soil layers and soil profiles. This is all the more true when working with apparent electrical resistivities.

The MUs 13 and 14 of the West area, covered by the D-D-taxon, are another example of the absence of soil type discrimination. Both MUs include deep Luvic Cambisols but the former has Luvic Cambisols developed on heavy clay and the latter on loam. This nondiscrimination may be due to a lack of resistivity contrast between the deep soil layers identified as heavy clay and loam, but also to the large depth of both soils whose bedrock appears beyond $95 \mathrm{~cm}$. The electrode arrays that we used were perhaps not large enough to differentiate between deep clay and loam layers.

In general, the nondiscrimination of different layers may be due not only to the low resistivity contrast between them but also to their geometrical characteristics. The impact of layers in the soil profile on electrical measurement is governed by the suppression principle that states that a thin layer sandwiched between two thicker others (about 5 times thicker) has little or no effect 
on electrical sounding. Thus, the BT layer of a Luvic Cambisols, even though strongly differentiated, may not affect electrical measurement if it is not thick enough.

\section{Conclusion}

This work proposes an original approach to process apparent electrical resistivity from multidepth surveys. The method, based on a geophysical taxonomy and using a parameter $\alpha$ to discriminate between layers, led to define nine taxa i.e. nine typical vertical resistivity profiles. Taxa mapping highlighted their spatial coherence, which was clearly related to pedological characteristics as for example the presence of a clay layer or the depth of the soil profile. By comparing soil and geophysical taxa maps, it was found that spatial delimitations of the geophysical taxa clusters matched the soil map boundaries quite well but less smoothly. Finally, each soil type could be assigned a specific geophysical taxon which was consistent with soil description.

This study opens a new way toward automatic soil mapping. The automatic resistivity profiling device and the data processing method proposed here can be useful tools to study the spatial variability of soil, especially when this variability is high and not related to extrinsic factors. Other experiments must be carried out in other pedological contexts or at other times in the year for studying the effect of the water content on the performance of the method.

\section{Acknowledgements}

The soil map of the Ouarville site has been drawn up in 2005 by P. Courtemanche, A. Dorigny, C. Lelay, J. Moeys, B. Nicoullaud, C. Pasquier and A. Couturier from the Unité de Science du Sol of INRA Orléans. The PhD and postdoc work of S. Buvat were funded by the FIRE (Fédération Ilede-France de Recherche sur l'Environnement, CNRS) and by the Labex Voltaire (ANR-10-LABX100-01), respectively. 


\section{References}

Agresti, A., 2002. Categorical Data Analysis, 2nd ed, John Wiley \& Sons, New York.

Auerswald, K., Simon, S., Stanjek, H., 2001. Influence of soil properties on electrical conductivity under humid water regimes. Soil Sci. 166, 382-390.

Basso, B., Amato, M., Bitella, G., Rossi, R., Kravchenko, A., Sartori, L., Carvahlo, L., Gomes, J., 2010. Two-dimensional spatial and temporal variation of soil physical properties in tillage systems using electrical resistivity tomography. Agron. J. 102, 440-449.

Batlle-Aguilar, J., Schneider, S., Pessel, M., Tucholka, P., Coquet, Y., Vachier, P., 2009. Axisymetrical infiltration in soil imaged by noninvasive electrical resistivimetry. Soil Sci. Soc. Am. J. 73, 510-520.

Besson, A., Cousin, I., Bourennane, H., Nicoullaud, B., Pasquier, C., Richard, G., Dorigny, A., King, D., 2010. The spatial and temporal organization of soil water at the field scale as described by electrical resistivity measurements. Eur. J. Soil Sci. 61, 120-132.

Besson, A., Cousin, I., Samouelian, A., Boizard, H., Richard, G., 2004. Structural heterogeneity of the soil tilled layer as characterized by $2 \mathrm{D}$ electrical resistivity surveying. Soil Tillage Res. 79, 239-249.

Brunet, P., Clement, R., Bouvier, C., 2010. Monitoring soil water content and deficit using Electrical Resistivity Tomography (ERT) - A case study in the Cevennes area, France. J. Hydrol. 380, 146-153.

Chaplot, V., Lorentz, S., Podwojewski, P., Jewitt, G., 2010. Digital mapping of A-horizon thickness using the correlation between various soil properties and soil apparent electrical resistivity. Geoderma 157, 154-164.

Chaplot, V., Walter, C., Curmi, P., Hollier-Larousse, A., 2001. Mapping field-scale hydromorphic horizons using Radio-MT electrical resistivity. Geoderma 102, 61-74.

Corwin, D.L., Lesch, S.M., 2005. Characterizing soil spatial variability with apparent soil electrical conductivity: I. Survey protocols. Comput. Electron. Agric. 46, 103-133.

Cousin, I., Besson, A., Bourennane, H., Pasquier, C., Nicoullaud, B., King, D., Richard, G., 2009. From spatial-continuous electrical resistivity measurements to the soil hydraulic functioning at the field scale. Comptes Rendus Geosci. 341, 859-867.

Dabas, M., Duval, O., Bruand, A., Verbèque, B., 1995. Cartographie électrique en continu : apport à la connaissance d'une couverture de sol développée sur matériaux deltaïques. Etude Gest. Sols 2, 257-268.

Dabas, M., Hesse A., Jolivet A., Tabbagh A., 1989. Intérêt de la cartographie de la résistivité électrique pour la connaissance du sol à grande échelle. Sci. Sol 27, 65-68.

Friedman, S.P., 2005. Soil properties influencing apparent electrical conductivity: a review. Comput. Electron. Agric. 46, 45-70.

Garre, S., Guenther, T., Diels, J., Vanderborght, J., 2012. Evaluating experimental design of ERT for soil moisture monitoring in contour hedgerow intercropping systems. Vadose Zone J. 11, 4.

Hesse, A., Jolivet, A., Tabbagh, A., 1986. New prospects in shallow depth electrical surveying for archaeological and pedological applications. Geophysics 51, 585-594.

Hosmer, D.W., Lemeshow, S., 2000. Applied Logistic Regression, 2nd edition. ed. John Wiley \& Sons, New York.

McCutcheon, M.C., Farahani, H.J., Stednick, J.D., Buchleiter, G.W., Green, T.R., 2006. Effect of soil water on apparent soil electrical conductivity and texture relationships in a dryland field. Biosyst. Eng. 94, 19-32.

Michot, D., Benderitter, Y., Dorigny, A., Nicoullaud, B., King, D., Tabbagh, A., 2003. Spatial and temporal monitoring of soil water content with an irrigated corn crop cover using surface electrical resistivity tomography. Water Resour. Res. 39, 1138-1157.

Moeys, J., Nicoullaud, B., Dorigny, A., Coquet, Y., Cousin, I., 2006. Cartographie des sols à grande échelle: intégration explicite d'une mesure de résistivité apparente spatialisée à l'expertise pédologique. Etude Gest. Sols 13, 269-286. 
Nicole, J., Coquet, Y., Vachier, P., Michelin, J., Dever, L., 2003. Fonctionnement hydrodynamique et différenciation pédologique d'une couverture de sol limoneux hydromorphe en Bassin Parisien. Etude Gest. Sols 10, 173-190.

Panissod, C., Dabas, M., Hesse, A., Jolivet, A., Tabbagh, J., Tabbagh, A., 1998. Recent developments in shallow-depth electrical and electrostatic prospecting using mobile arrays. Geophysics $63,1542-1550$.

Panissod, C., Dabas, M., Jolivet, A., Tabbagh, A., 1997a. A novel mobile multipole system (MUCEP) for shallow $(0-3 \mathrm{~m})$ geoelectrical investigation: the "Vol-de-canards" array. Geophys. Prospect. 45, 983-1002.

Panissod, C., Lajarthe, M., Tabbagh, A., 1997b. Potential focusing: a new multielectrode array concept, simulation study, and field tests in archaeological prospecting. J. Appl. Geophys. $38,1-23$.

Panissod, C., Michot, D., Benderitter, Y., Tabbagh, A., 2001. On the effectiveness of 2D electrical inversion results: an agricultural case study. Geophys. Prospect. 49, 570-576.

Robain, H., Lajarthe, M., Florsch, N., 2001. A rapid electrical sounding method The «three-point» method: a Bayesian approach. J. Appl. Geophys. 47, 83-96.

Samouelian, A., Cousin, I., Richard, G., Tabbagh, A., Bruand, A., 2003. Electrical resistivity imaging for detecting soil cracking at the centimetric scale. Soil Sci. Soc. Am. J. 67, 1319-1326.

Samouëlian, A., Cousin, I., Tabbagh, A., Bruand, A., Richard, G., 2005. Electrical resistivity survey in soil science: a review. Soil Tillage Res. 83, 173-193.

Samouelian, A., Richard, G., Cousin, I., Guerin, R., Bruand, A., Tabbagh, A., 2004. Threedimensional crack monitoring by electrical resistivity measurement. Eur. J. Soil Sci. 55, 751-762.

Séger, M., Cousin, I., Frison, A., Boizard, H., Richard, G., 2009. Characterisation of the structural heterogeneity of the soil tilled layer by using in situ 2D and 3D electrical resistivity measurements. Soil Tillage Res. 103, 387-398.

Seladji, S., Cosenza, P., Tabbagh, A., Ranger, J., Richard, G., 2010. The effect of compaction on soil electrical resistivity: a laboratory investigation. Eur. J. Soil Sci. 61, 1043-1055.

Souffaché, B., Cosenza, P., Flageul, S., Pencolé, J.-P., Seladji, S., Tabbagh, A., 2010. Electrostatic multipole for electrical resistivity measurements at the decimetric scale. J. Appl. Geophys. 71, 6-12.

Tabbagh, A., Dabas, M., Hesse, A., Panissod, C., 2000. Soil resistivity: a non-invasive tool to map soil structure horizonation. Geoderma 97, 393-404.

Tabbagh, A., Panissod, C., Guérin, R., Cosenza, P., 2002. Numerical modeling of the role of water and clay content in soils' and rocks' bulk electrical conductivity. J. Geophys. Res.-Solid Earth Planets 107, ECV 20.1-ECV 20.9.

Tabbagh, J., Samouëlian, A., Tabbagh, A., Cousin, I., 2007. Numerical modelling of direct current electrical resistivity for the characterisation of cracks in soils. J. Appl. Geophys. 62, 313323.

Tetegan, M., Pasquier, C., Besson, A., Nicoullaud, B., Bouthier, A., Bourennane, H., Desbourdes, C., King, D., Cousin, I., 2012. Field-scale estimation of the volume percentage of rock fragments in stony soils by electrical resistivity. Catena 92, 67-74. 


\section{Figure captions}

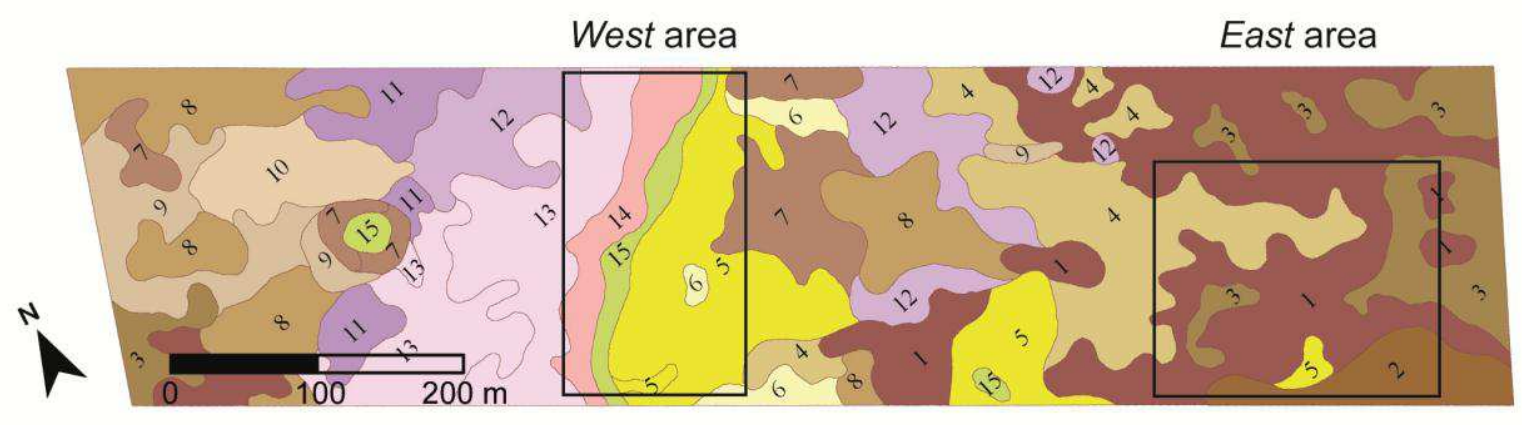

Soils developed from loess and Beauce limestone

1. Luvic Cambisols over cryoturbed limestone at $70-77 \mathrm{~cm}$ depth

2. Deep Luvic Cambisols over heavy clay

3. Luvic Cambisols over cryoturbed limestone at 55-60 cm depth

4. Complex unit of shallow Hypereutric Cambisols and Luvic Cambisols

5. Shallow Calcaric Cambisols and shallow stony Hypereutric Cambisols

6. Shallow weakly stony Hypereutric Cambisols

Soils developed from loess and buhrstone clay

7. Hypereutric Cambisols over buhrstone clay

8. Weakly stony Luvic Cambisols over deep stony buhrstone clay

9. Stony Luvic Cambisols over stony buhrstone clay and limestone

10. Stony Luvic Cambisols over stony buhrstone clay and deep limestone

11. Deep weakly stony Luvic Cambisols over heavy buhrstone clay and decarbonatation clay

12. Weakly stony Luvic Cambisols over heavy buhrstone clay and limestone

13. Weakly stony Luvic Cambisols over heavy buhrstone clay and deep limestone

Talweg and slopetow soils

14. Deep Luvic Cambisols over redish loam

15. Colluvic Cambisols (deep in the two dolines)

Figure 1. Soil map of the field with the two surveyed areas West and East. The World Reference Base for Soils (IUSS, 2007) is used in the legend. "Shallow" and "deep" refer to soils whose bedrock generally appears above the $50 \mathrm{~cm}$ depth and at more than $80 \mathrm{~cm}$, respectively. 


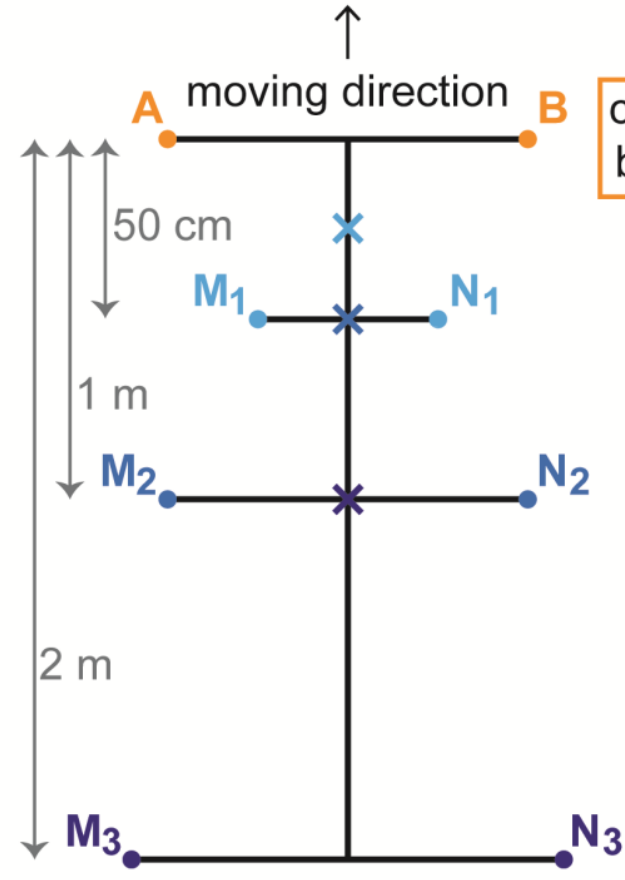

(a) current injection

by 2 electrodes

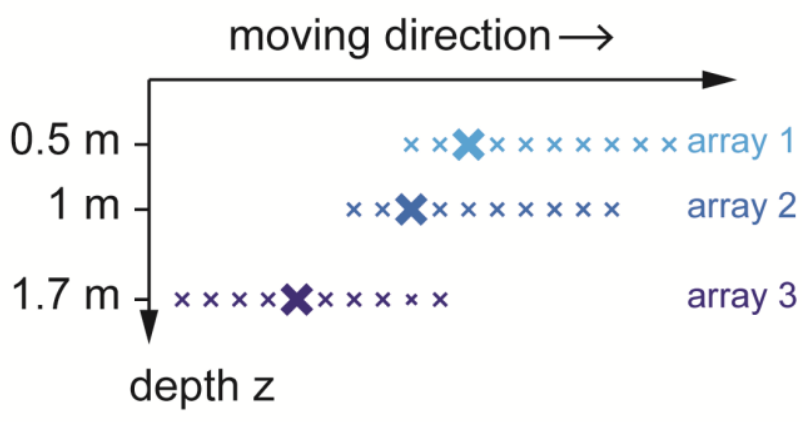

(b)

Figure 2. a) Configuration and dimensions of the automatic resistivity profiling device (crosses show the 3 measurement locations) and b) principle of multi-depth measurements (big crosses show the depths of investigation at $0.5,1$ and $1.7 \mathrm{~m}$ of the 3 measurements corresponding to the 3 electrode arrays). 


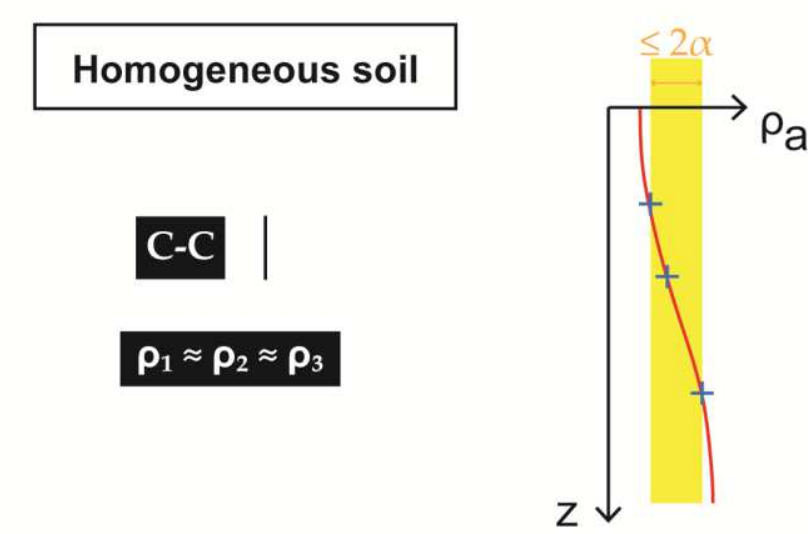

2-layers soils

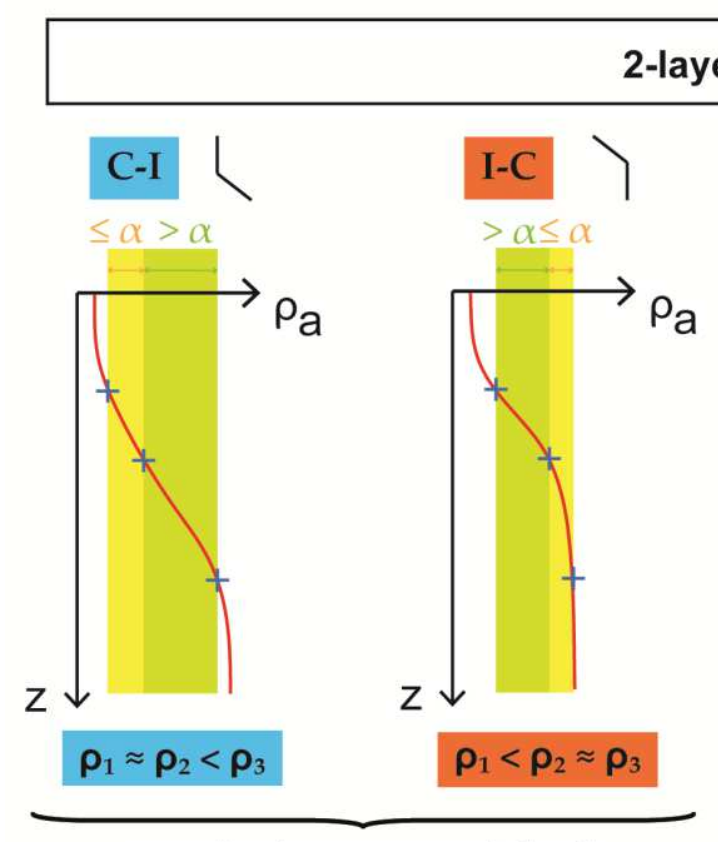

conductor over resistant
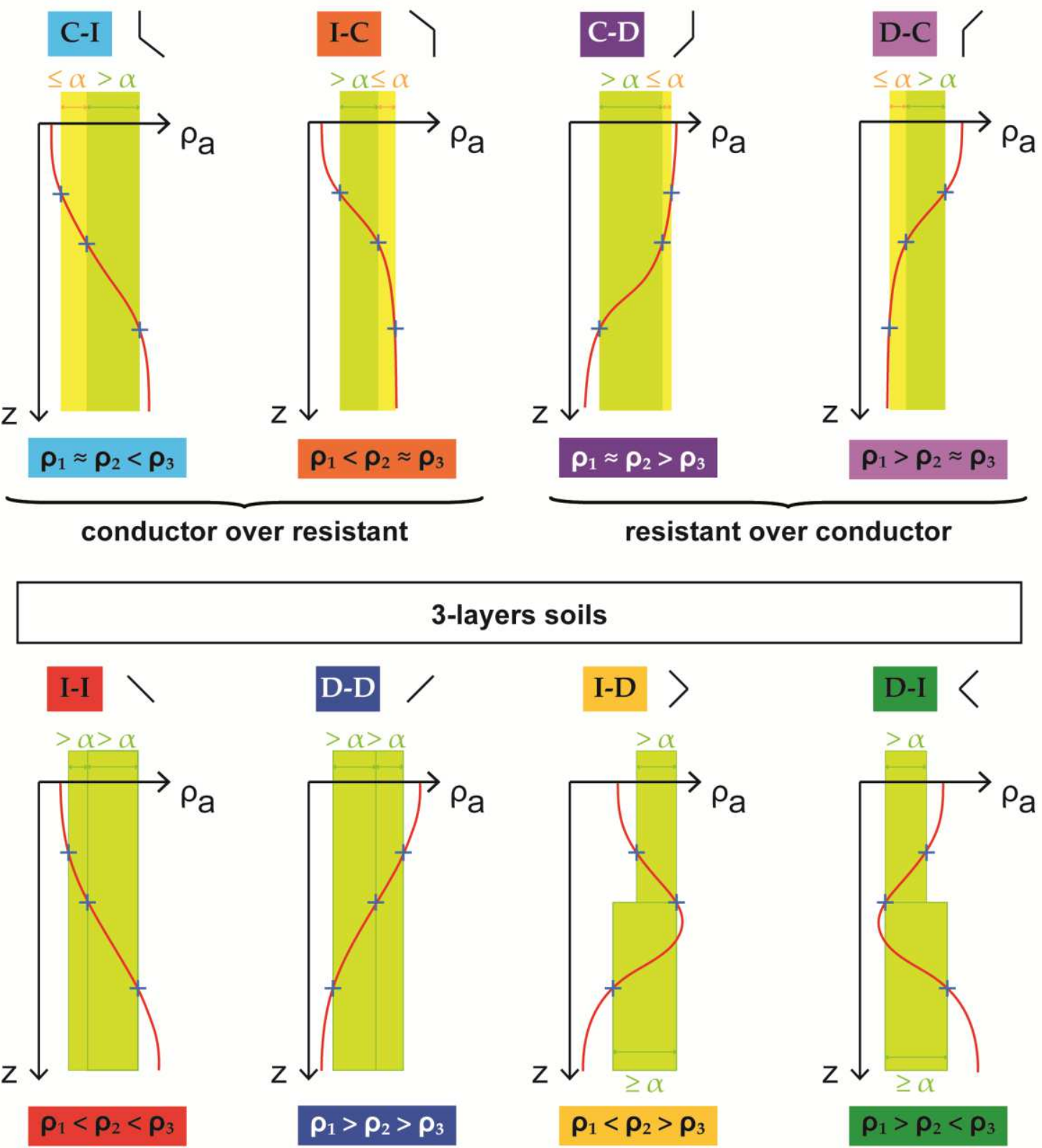

Figure 3. Geophysical taxa definition, names, symbols and color code. 


$$
\begin{aligned}
& \rho_{\mathrm{a} 1} \rightarrow \rho_{\mathrm{a} 2} \quad \rho_{\mathrm{a} 2} \rightarrow \rho_{\mathrm{a} 3} \quad E \text { matrix } \\
& {\left[\begin{array}{l}
\searrow \\
1
\end{array}\right] \times[\searrow \mid /]=\left[\begin{array}{lll}
\searrow & \rangle \\
& 1 & J \\
\langle & & /
\end{array}\right] \Longleftrightarrow\left[\begin{array}{ccc}
\text { I-I } & \text { I-C } & \text { I-D } \\
\text { C-I } & \text { C-C } & \text { C-D } \\
\text { D-I } & \text { D-C } & \text { D-D }
\end{array}\right]}
\end{aligned}
$$

Figure 4. Principle of construction of the experimental geophysical taxon matrix $E$.

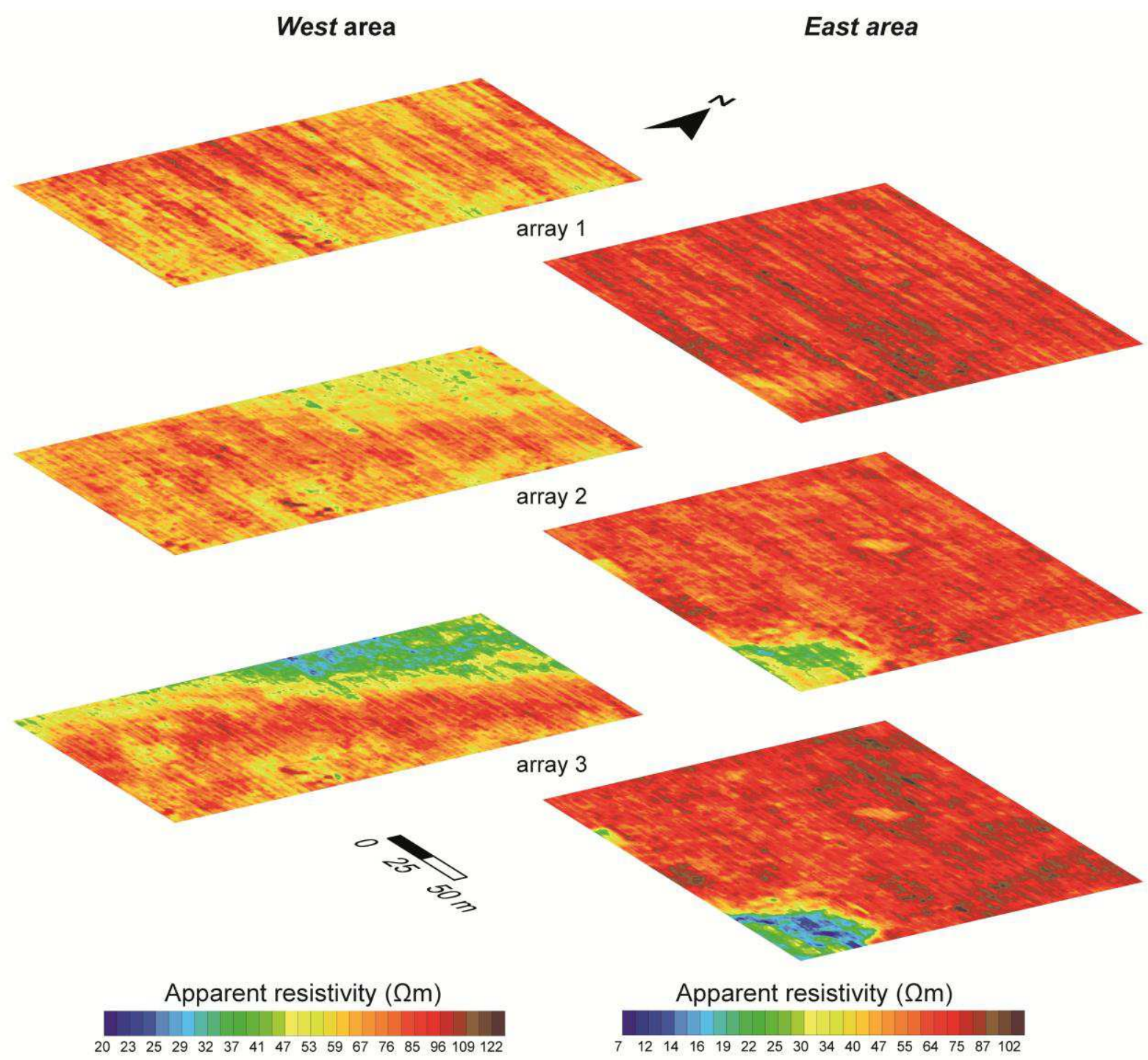

Figure 5. Apparent resistivity maps of areas West and East. Arrays 1, 2 and 3 correspond to volume of soil investigated from the surface down to $0.5,1$ and $1.7 \mathrm{~m}$ depth, respectively. 


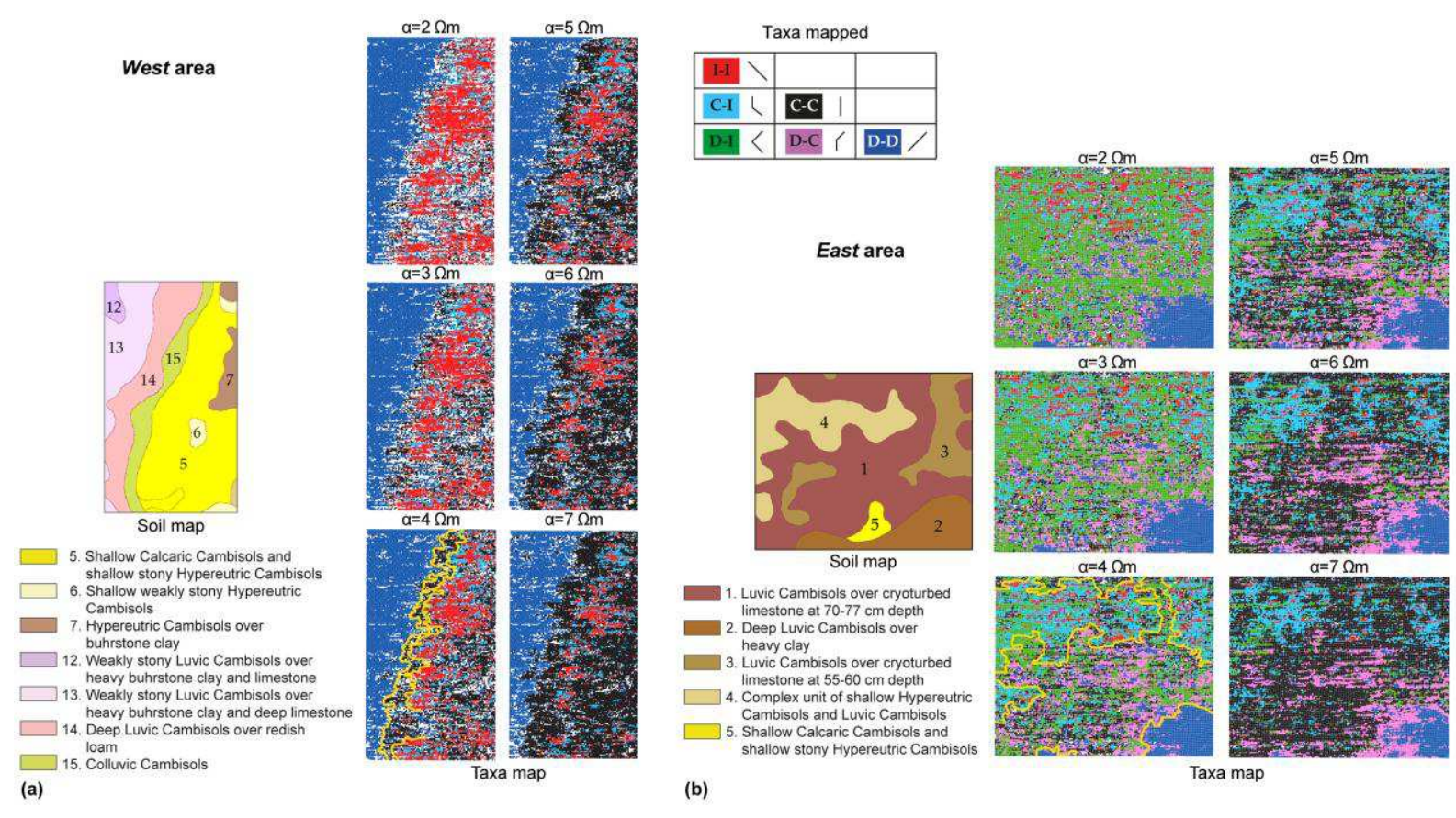

Figure 6. Spatial distribution of geophysical taxa in each area for $\alpha$ from 2 to $7 \Omega \mathrm{m}$ and comparison with soil map excerpt from Figure 1 for a) the West area, and b) the East area. Soil map boundaries can be compared to geophysical taxa cluster delineations for $\alpha=4 \Omega \mathrm{m}$. 


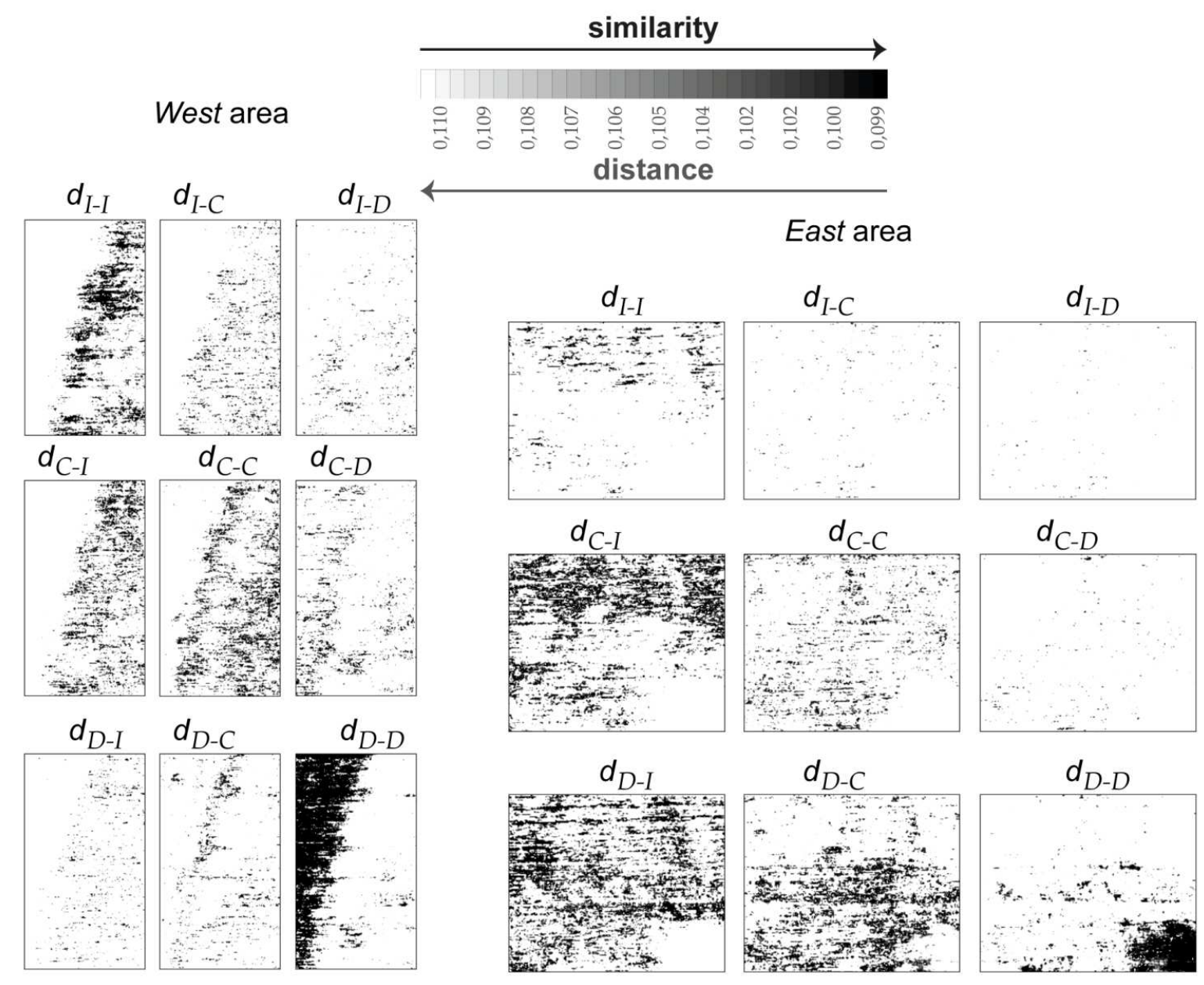

Figure 7. Maps of similarity between experimental electrical soundings and reference geophysical taxa for a) the West area, and b) the East area. 

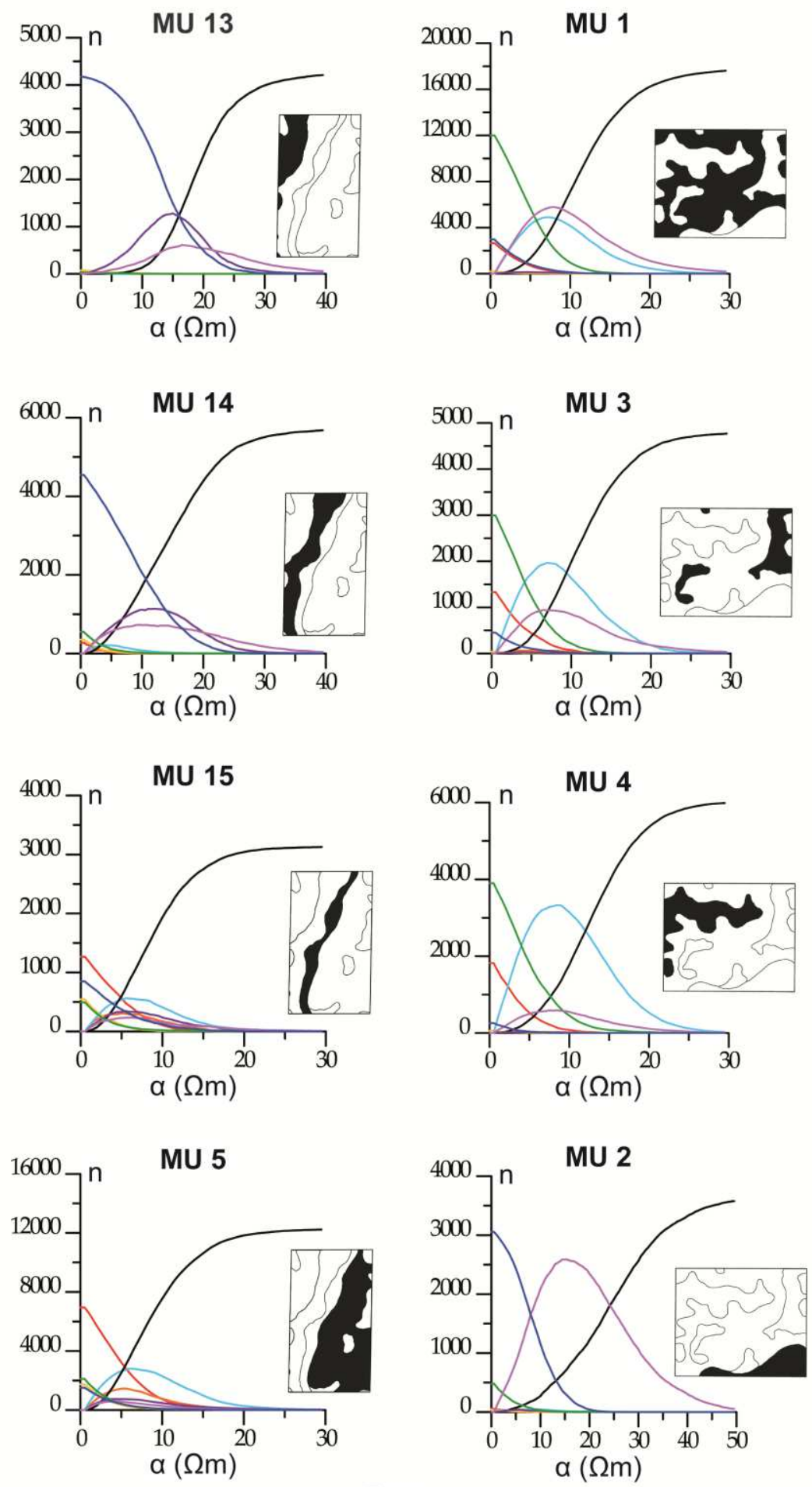

Taxa

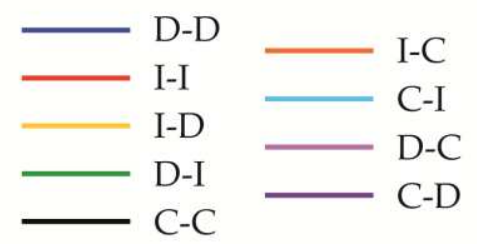

Figure 8. Evolution of geophysical taxa occurrences as a function of $\alpha$ value for the main map units of areas West (left) and East (right). 
Table 1. Summary description of the map units encountered in each surveyed area ( $\mathrm{s}$ is the standard deviation calculated on the $\mathrm{n}$ auger soundings), expected and observed geophysical taxa for each map unit and values of the $\alpha$ parameter for which reference taxa were consistent with experimental taxa (taxa in bold).

\begin{tabular}{|c|c|c|c|c|c|c|}
\hline Area & $\begin{array}{l}\text { Map } \\
\text { Unit }\end{array}$ & Soil type & $\begin{array}{l}\text { Bedrock } \\
\text { depth }(\mathrm{cm})\end{array}$ & $\begin{array}{l}\text { Expected } \\
\text { taxa }\end{array}$ & $\begin{array}{c}\text { Observed } \\
\quad \text { taxa } \\
\text { (for } \alpha=4 \Omega \mathrm{m} \text { ) }\end{array}$ & $\begin{array}{c}\alpha \text { values for a } \\
\text { correct fit } \\
(\Omega \mathrm{m})\end{array}$ \\
\hline \multirow{4}{*}{ West } & 13 & $\begin{array}{l}\text { Deep Luvic Cambisols on } \\
\text { clay and limestone }\end{array}$ & $\begin{array}{l}>95 \\
(\mathrm{n}=4)\end{array}$ & D-D & D-D & $0<\alpha<16$ \\
\hline & 14 & $\begin{array}{l}\text { Deep Luvic Cambisols on } \\
\text { loam }\end{array}$ & $\begin{array}{l}>100 \\
(\mathrm{n}=7)\end{array}$ & D-D & D-D & $0<\alpha<11$ \\
\hline & 5 & $\begin{array}{l}\text { Shallow Calcaric Cambisols } \\
\text { and shallow Hypereutric } \\
\text { Cambisols }\end{array}$ & $\begin{array}{c}37 \\
(s=6)(n=10)\end{array}$ & C-I & I-I \& C-I & $\alpha \approx 7$ \\
\hline & 15 & Colluvic Cambisols & $\begin{array}{c}55 \\
(\mathrm{~s}=14)(\mathrm{n}=2)\end{array}$ & C-C & $\mathrm{C}-\mathrm{C}$ & $\alpha \geq 5$ \\
\hline \multirow{5}{*}{ East } & 2 & $\begin{array}{l}\text { Deep Luvic Cambisols on } \\
\text { heavy clay }\end{array}$ & $\begin{array}{c}>105 \\
(\mathrm{n}=2)\end{array}$ & D-D & D-D & $0<\alpha<8$ \\
\hline & 1 & Luvic Cambisols & $\begin{array}{c}75 \\
(\mathrm{~s}=11)(\mathrm{n}=20)\end{array}$ & D-I & D-I & $0<\alpha<5.5$ \\
\hline & 3 & Luvic Cambisols & $55(n=1)$ & D-I \& C-I & I-I \& C-I & $4.5<\alpha<9.5$ \\
\hline & \multirow{2}{*}{4} & Luvic Cambisols & $\begin{array}{c}55 \\
(\mathrm{~s}=6)(\mathrm{n}=8)\end{array}$ & \multirow{2}{*}{ D-I \& C-I } & \multirow{2}{*}{ I-I \& C-I } & \multirow{2}{*}{$4<\alpha<12$} \\
\hline & & Hypereutric Cambisols & $\begin{array}{c}40 \\
(s=5)(n=3)\end{array}$ & & & \\
\hline
\end{tabular}

Table 2. Prediction (in percent) of soil map units (Figure 1) from geophysical taxa using multinominal logistic regression and $\alpha$ value for which the soil map unit is best predited

\begin{tabular}{|c|c|c|c|c|c|}
\hline \multicolumn{7}{|c|}{ West area } \\
\hline from \to & 13 & 14 & 15 & 5 & $\alpha(\Omega \mathrm{m})$ \\
\hline 13 & 96.1 & 0.7 & 0.0 & 3.2 & 3 \\
\hline 14 & 0.0 & 76.5 & 0.0 & 23.5 & 2 \\
\hline 15 & 13.1 & 6.5 & 0.0 & 80.4 & 4 \\
\hline 5 & 1.1 & 1.9 & 0.0 & 97.0 & 7 \\
\hline from $\backslash$ to & 1 & 2 & 3 & 4 & $\alpha(\Omega \mathrm{m})$ \\
\hline 1 & 96.3 & 2.1 & 0.0 & 1.6 & 7 \\
\hline 2 & 22.0 & 78.0 & 0.0 & 0.0 & 2 \\
\hline 3 & 87.2 & 2.8 & 0.0 & 10.0 & 4 \\
\hline 4 & 85.5 & 1.2 & 0.0 & 13.3 & 3 \\
\hline
\end{tabular}

